\section{The Changes in Matrix Metalloproteinases and Collagens Expression of Rat Articular Cartilage after Continuous Mandibular Advancement: Immunohistochemical Study}

\section{Abstract}

Condylar growth modification is induced by mandibular advancement though the changes in Temporomandibular Joint (TMJ) after mandibular advancement could be permanently stable are not yet proved. Therefore, our purpose is to investigate the effects of mandibular advancement on the rat TMJ by changing in Matrix Metalloproteinases (MMPs) and Collagens (COLs) expression immunohistochemically (IHC) after retention treatment. In this study, 54 male Sprague-Dawley rats were divided to control group $(n=24)$ and experimental group $(n=30)$ for three months subgroups period. Only experimental sub-groups were subjected to a full-time orthodontic inclined methyl methacrylate bite plate cemented to the incisors to advance the mandible for one month and continued as a half-day-wearer (retention period) till the end of the $2^{\text {nd }}$ month and stayed without appliance during whole $3^{\text {rd }}$ month (post retention period). Then, the assessment of gross-morphological changes of skull and the examination of the articular cartilage for each sub-group histologically in addition to IHC examination for MMP-1, MMP 8 and MMP 13 and COL-I, II and III were done. The grossmorphological changes were clear in experimental group as downward forward mandibular advancement in addition to a high significant decreased in the base mandibular length. There was also an abundant cellular proliferation at the condylar cartilage with a significant condylar ossification and higher osteoblastic activity in the experimental group obviously at retention period. Moreover, a significant increase in MMP-13 expression in both differentiation and hypertrophic layers of an experimental group during active and retention periods with reduction in the expression of COL-II in the experimental group was observed with no significant changes in other markers. These upregulation of MMP-13 in associated with significant reduction in expression of COL-II plays a significant role in cartilage collagen degradation and treatment stability, which is confirmed through the post-retention period due to endochondral ossification pattern improvement.

Keywords: Matrix metalloprotienases; Collagens; Mandibular advancement; Mandibular condylar cartilage; Morphological changes
Wisam W. Alhamadi1*, Fayez Saleh ${ }^{2}$, Essam Osman ${ }^{3}$ and Mazin J. Musa ${ }^{4}$

1 Division of Orthodontics, College of Dentistry, University of Misan, Amarah City, Maysan, Iraq

2 Division of Orthodontics, Beirut Arab University, Beirut, Lebanon

3 Department of Dental Biomaterial, Beirut Arab University, Beirut, Lebanon

4 Clinical Laboratory Sciences Department, College of Pharmacy, University of Babylon, Babylon, Iraq

\section{*Corresponding author: Al-Hamadi WW \\ $\equiv$ wisam.alhamadi@gmail.com}

Assistant Professor, University of Misan, Amara City, Maysan, Iraq.

Tel: +9647703378030

Citation: Alhamadi WW, Saleh F, Osman E, Musa MJ (2018) The Changes in Matrix Metalloproteinases and Collagens Expression of Rat Articular Cartilage after Continuous Mandibular Advancement: Immunohistochemical Study. J Orthod Endod Vol.4 No.1:5

\section{Introduction}

Orthodontic appliances and their impact on the growth of the mandibular condyles in experimental animal models have still one of the important ways to explore the real changes that could have a role in optimization of the orthodontic treatment in the last decades [1]. Planning for the retention phase as a part of the orthodontic treatment requires knowledge for the biology of the jaw response to the treatment [1,2]. The articular condylar growth modification that induced by mandibular advancement as reported by Petrovic et al. [3] depending on histological assessment while other studies assessment were by Immunehistochemically (IHC), morphometrically, biochemically or auto-radiographically as diagnostic tools to evaluate the 
growth at condyle or to detect increased expression of some growth factors and biomarkers.

The stability of the changes in Temporomandibular Joint (TMJ) by orthodontic appliance is not yet proved. Therefore, estimation of Collagens (COLs) with degradation enzymes as Matrix Metalloproteinases (MMPs) can give a sign for permanency and effectiveness of treatment. Mechanical overload by the appliance acts on the cartilage cells to stimulate MMPs which are involved in the degradation of collagens as well as in tissue destruction in a variety of inflammatory lesions. MMP-1 is produced by fibroblasts, synovial cells, macrophages, endothelial cells, and carcinoma cells, and degrades COL-I, II, III, VII and X collagen. MMP-8 is released by neutrophils in inflammatory tissue and degrades COL-I, II and III [4-9]. Furthermore, MMP-13 is observed in tumors, osteoarthritis, rheumatism, and wounds. It degrades COL-I, II, III and X, it is considered to be the strongest for degrading COL-II specifically [4-10]. MMP-13 appears to be one of the most important MMPs in cartilage remodeling and mineralization because it exhibits a substrate preference for the cartilage, specifically COL-II [11]. Moreover, MMP-13 plays a role in making space of cell enlargement by degradation of the cartilage matrix and initiation of mineralization during the early stage of development [12]. The aim of present study was to investigate the effects of mandibular advancement on the rat TMJ by changing in MMP-1, MMP-8 and MMP-13 and COL-I, II and III expression by IHC during and after retention treatment with their relevant gross and microscopic histological changes.

\section{Material and Methods}

\section{Experimental design and animals}

Fifty four male Sprague-Dawley rats (4 weeks old), weight (100$120 \mathrm{gm}$ ) were used in this study. The rats divided into 2 groups; a control group and experimental group. After anaesthetizing the rats in experimental group by injection of $40 \mathrm{mg} / \mathrm{ml}$ thiopental sodium intra-peritoneally, they were subjected to an orthodontic inclined bite-plane (fixed functional appliance) placement at upper anterior incisor. All groups were fed standard food ad libitum and were kept under the same environmental condition at a constant temperature during the whole period of the experiment. Animals were cared for in accordance with the principles for the care, use and protection of experimental animals as set by Beirut Arab University institutional animal care and committee.

1. Control group: It was divided into 3 sub-groups, a, b, and $c$ ( $n=8$ for each) without any advancing forces.

2. Experimental group: It was divided into 3 subgroups, $d$, e and $f(n=10$ for each $)$ :

Sub group-I(d): Sacrificed after one month of treatment (24 hrs wearing fixed functional appliance).

Sub group-2(e): Sacrificed after two months of treatment $\left(1^{\text {st }}\right.$ month with $24 \mathrm{hrs}$ treatment and retention period at the $2^{\text {nd }}$ month (12 hrs treatment).

Sub group-3(f): Sacrificed after three months of treatment $\left(1^{\text {st }}\right.$ month with 24 hrs treatment, retention period at the $2^{\text {nd }}$ month and without appliance at the $3^{\text {rd }}$ month (post-retention period).

\section{Appliance Preparation and Fitting}

The appliances were used of a similar mode of action to those used with humans, such as (forcus, Jasper jumper, Herpst and an inclined plane).

The appliance was a bite jumping device of acrylic type, made up of poly methyl methacrylate (PMMA) $[13,14]$. Fitting the appliances was done using cement dental material (Ketac Cem3M ESPE AG Dental Product-Germany) as radiopaque glass ionomer luting cement used for cementation of crowns and bridges and orthodontic strips cementation, the appliance was positioned to all experimental group by an inclined anterior bite plane, $20-25^{\circ}$ inclination with constant force that it caused mandibular foreword-downward positioning during the rats' rest and functional bite (Figure 1).

\section{Weight Gain Recording}

The weight was recorded weekly throughout the experiment for both main groups. This was done to evaluate and compare the somatic growth status between the experimental and control groups, all measurements were done at 9 am [15].

\section{The Sampling}

The dissected jaw and part of the cranium were put in buffered formalin solution (40\% formaldehyde $100 \mathrm{cc}$, distilled water $900 \mathrm{cc}, 4 \mathrm{gm}$ sodium phosphate monobasic and $6.5 \mathrm{gm}$ sodium phosphate of basic anhydrous), 12 hrs preliminary fixation time.

\section{Morphological Observation of Skull}

Digital pictures of the rats' right mandibles lateral view were taken using a color video camera (Digital still camera Sony group-DSC-HX1) for gross morphological changes and analysis. Linear measurement from (point F-the most inferior "posterior" point of condyle) to (point A-the most anterior point of alveolar bone) directly in the mandible of rats to estimated mandibular length, after the heads of animals were carefully dissected along the middle sagittal plane using a vernier caliper (DentariumGermany), then measure the mandibular base length between point $A$ and point $B$-the midpoint of mandibular foramen (Figure 2A). The mandible was mounted at $90^{\circ}$ angle at a fixed distance from digital camera [16].

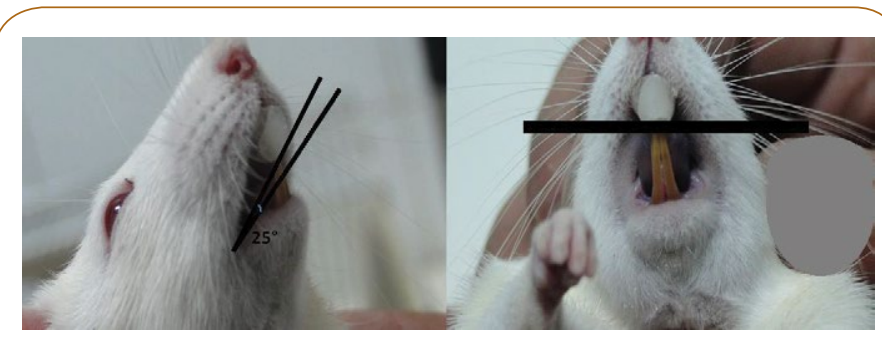

Figure 1 The bite-jumping appliance fitted for mandibular advancement. 


\section{Tissue Preparation}

Sectioning of the paraffin specimen was done by a rotator microtome (Leitz 1516, Lecica Microsystems, Wetzlar, Germany) at $7 \mu \mathrm{m}$ thickness followed by staining in haematoxyline and eosin, and examined under the light microscope [17]. The measurements of different layers of articular condyle were done histologically using digital AXIOVISION software imaging (carles zeiss-Germany) which was split into three portions at the midpoint of the horizontal line drawn from the most prominent part of the articular condyle (Figure 2B).

\section{IHC Examinations}

Areas stained for COLs and MMPs of hot-spot reaction in the posterior area of the upper part of articular condyle [18]. The specific primary antibodies used were anti-MMP 1 antibody (Ab) Rabbit polygonal to MMP 1 ( $50 \mu \mathrm{g}-0.2 \mathrm{mg} / \mathrm{ml}$-abcam, USA), antiMMP 8 (H-300) Ab Rabbit polygonal to MMP 8 (200 $\mu$ g-Santa Cruz biotecnology, USA), anti-MMP 13 Ab Rabbit polygonal to MMP 13 (100 $\mu \mathrm{g}-1 \mathrm{mg} / \mathrm{ml}$-abcam, USA), anti-Collagen-I (Col-1) Ab mouse monocolonal to Col-I (abcam, USA), anti-Collagen II (Col-II) colon 2B1.5 Ab mouse monoclonal to Col-II (200 $\mu$ g-Thermo scientific, USA), and the anti-Collagen III (Col-III) Ab Rabbit polyclonal to Col-III (100 $\mu$ l-Thermo scientific, USA). The secondary antibodies were goat anti-rabbit IgG (200 $\mu$ g-Santa Cruz biotecnology, USA) (with MMP-1, MMP-8, MMP-13 and COL-III) and goat anti-mouse IgG (200 $\mu \mathrm{g}-$ Santa Cruz biotechnology, USA) (with COL-I and COLII).

IHC was carried out using method of de-waxing and rehydrating, then treating with glycine ( 1 in 10 Phosphate Buffer (PBS) and 0.3$3 \%$ hydrogen peroxide $\mathrm{H}_{2} \mathrm{O}_{2}$ and $100 \%$ methanol for 10 minutes at room temperature to quench endogenous peroxidase and retrieve the antigen. Non-specific bindings were blocked with $1 \%$ Bovine Serum Albumin (BSA) in Tris Buffer (TBS) pH 7.4 for 30 minutes at $20^{\circ} \mathrm{C}$; then the samples were incubated with primary $\mathrm{Ab}$. Free antibodies were removed by washing the samples in PBS thoroughly; then, sections were incubated with the secondary antibody followed by washing. Then, the slides were dipped in 3,3-diaminobenzidine (DAB) in chromogen solution (DAKO liquid DAB + substrate chromogen system, Code, Denemark) for 2-7 minutes to identify the binding sites. Sections were finally counterstained with Mayer's hematoxyline for background staining.

\section{Statistical Analysis}

The data are expressed as the mean \pm SEM and were analyzed using two-way ANOVA. The significance level for all analyses was set at a probability $(P)$ of less than 0.05 . All analyses were performed by GraphPad Prism 5.3 for windows (GraphPad Software, San Diego, CA, USA).

\section{Results}

\section{Body weight}

The body weight in both groups increased progressively, and significant differences $(p<0.05)$ were observed only from $5^{\text {th }}$ to $10^{\text {th }}$ week. However, in the end of the experiment, no significant differences were observed between the experimental and control groups.

\section{Morphological changes}

Grossly, downward forward mandibular advancement caused a significant increase in the length of the mandible at the experimental sub-groups $(p<0.001)$ at the end of the $2^{\text {nd }}$ month (retention period) with a lesser degree $(p<0.05)$ at the end of the $3^{\text {rd }}$ month (post-retention period) vs control. Regarding the mandibular base, there were a significant increase in $1^{\text {st }}$ period of experimental sub-group $(p<0.01)$ and recovered to reach the original level recording non-significant change in both retention and post retention periods vs. control (Figure 3).

\section{Histological examination}

The effects of the bite-jumping appliance in young rats showed great substantial histological changes in TMJ region. At the $1^{\text {st }}$ month, histological examination of articular condyle for experimental group revealed a significant increase in proliferative zone $(p<0.05)$ vs. control with no significant changes in other two zones (fibrous and hypertrophic). At the $2^{\text {nd }}$ month (retention period), fibrotic zone had a significant increase $(p<0.05)$ vs. control; however, both proliferative and hypertrophic zone decreased but became significantly only in hypertrophic zone $(p<0.05) v s$. control. Regarding to the $3^{\text {rd }}$ month (post-retention), there is no significant changes in fibrotic and proliferative zones in comparison with control, while the hypertrophic zone revealed significant decrease $(p<0.001)$ vs. control (Figure 4).

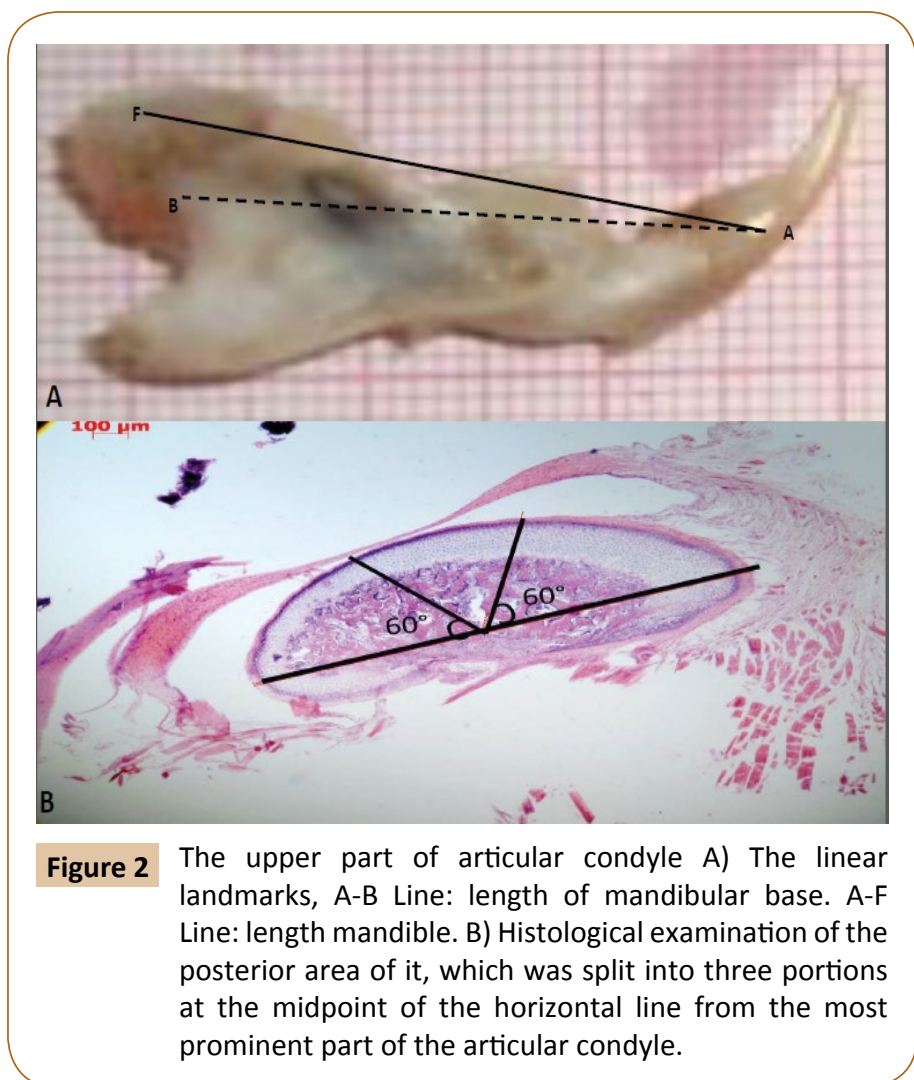




\section{IHC examination for COLs expression}

The extracellular matrix of the proliferation and the differentiation layers were positively stained for COL- $\mathrm{I}$ in both control and experimental groups at $1^{\text {st }}$ month, while progressive decrease was noticed from the $2^{\text {nd }}$ to $3^{\text {rd }}$ month but still non-significant in comparison with control group (Figure 5).

The positive findings for COL-II were observed in the extracellular matrix of all proliferation, differentiation and hypertrophy layers throughout the experimental period with significant decrease $(p<$ 0.05 ) in comparison to that of the control group at $1^{\text {st }}$ (proliferation and differentiation layers) and $2^{\text {nd }}$ month (differentiation and hypertrophy layers), with no significant decrease at the $3^{\text {rd }}$ month in comparison with the control (Figure 6).

The positive findings were identified for COL-III in the extracellular area matrix of the proliferation and differentiation layers throughout the experimental period with no significant differences were observed between the experimental and control groups (Figure 7).

\section{IHC examination for MMPs expression}

In both, control and experimental groups, the positive findings of MMP-1 were observed in the cellular matrix area of the proliferation and differentiation layers at approximately the same level, with non-significant differences (Figure 8).

The positive findings of MMP- 8 were observed in the cellular area of the differentiation and hypertrophy layers in both control and experimental groups' throughout the experiment. Subsequently, the levels of staining gradually and progressively increased nonsignificantly in the experimental group at $1^{\text {st }}, 2^{\text {nd }}$ and $3^{\text {rd }}$ months

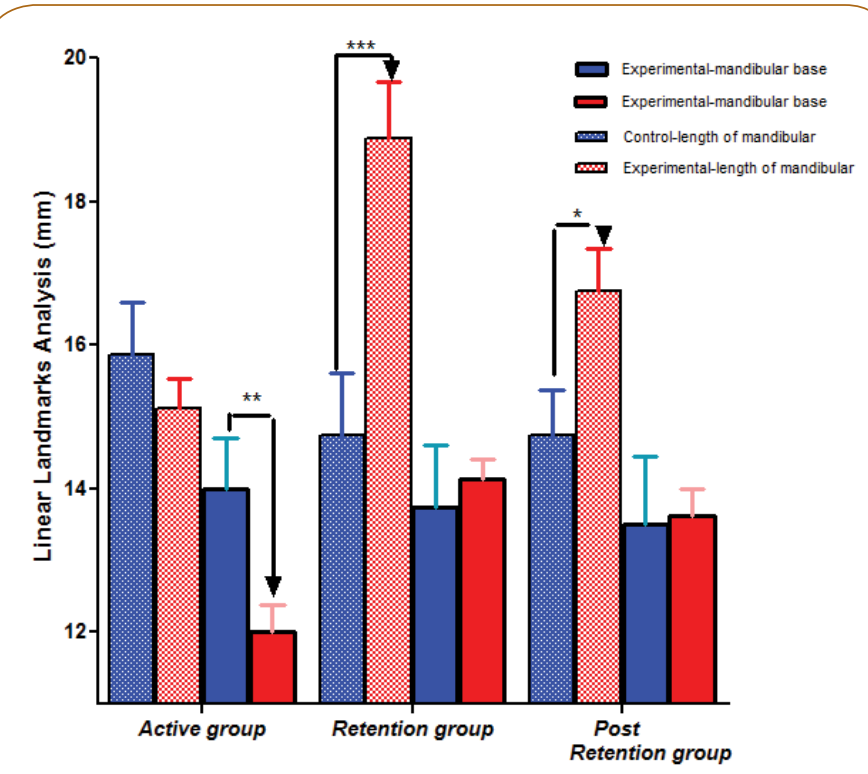

Figure 3 Linear measurements analysis of mandibular length line and mandibular base line in control group and experimental group (active, retention and post-retention treatment). The number of asterisks $\left({ }^{*}\right)$ correspond to the level of the statistical significance $(* * P<0.01, * * * P$ $<0.001)$. All values refer to mean \pm SEM.
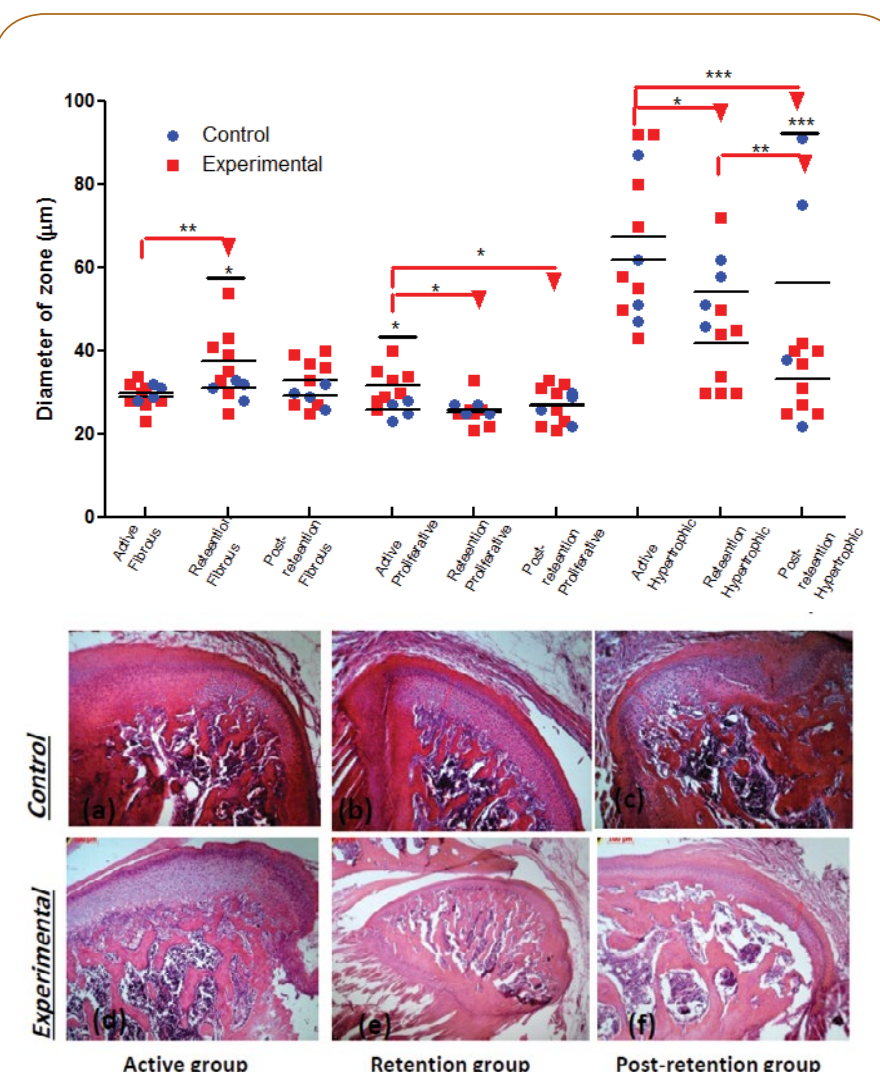

Figure 4 Histopathological findings (hematoxylin-eosin) (bar: 100 $\mu m) .(a-c)$ in control and (d-f) experimental rat groups (active (d), retention (e) and post-retention treatment (f)). The number of asterisks $\left({ }^{*}\right)$ correspond to the level of the statistical significance $\left({ }^{*} P<0.05,{ }^{* *} P<0.01, * * * P\right.$ $<0.001)$. All values refer to mean \pm SEM.

vs. control (Figure 9).

The positive findings for MMP-13 were observed in the cellular matrix area of the differentiation and proliferation layers throughout the experimental period. There was a progressive non-significant increase in the experimental group in the $1^{\text {st }}$ month vs. control. Subsequently, the increase became significant $(p<0.05)$ at the $2^{\text {nd }}$ and $3^{\text {rd }}$ month in comparison with the control. In spite of the progressive increase of the experimental group over 3 months, there was no significant differences were observed between the sub-groups (Figure 10).

\section{Discussion}

The bite-jumping appliance is used to move the mandible to an advancement position while slightly opening the bite [19]. The transition of the condyle towards the articular eminence with posterior-inferior rotation of the entire mandible causes a reduction in superior joint spaces in the condyle while posterior joint space increases. This function applies stretching forces to the distal, distal-superior part of the condyle, and the areas of the glenoid fossa that face the areas of the condyle [20-22]. As adverse effects for these appliances on the body weight, a slight and statistically non-significant decrease in weight gain of experimental group and this might due to the adverse effects 


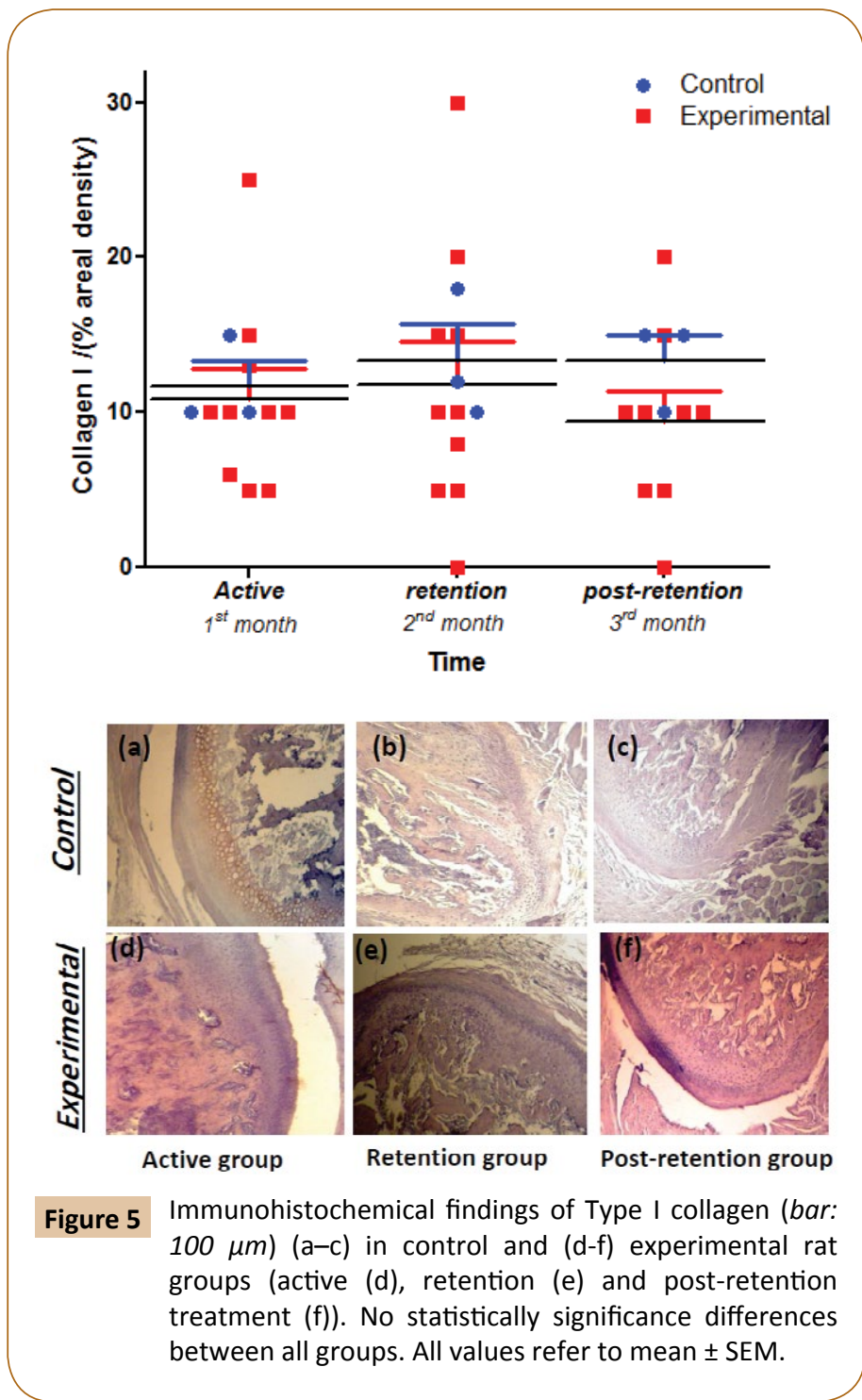

of attaching plate on the eating [20]. Therefore, we considered these changes in the body weight were transiently and could be disregarded.

The analysis of manual linear measurements was recommended by separating analysis to estimate the errors of linear measurements. The findings had no significant effect neither on the condylar changes nor symmetrical morphological changes regarding grossly linear measurements on the mandible $[17,23]$.

The six different histological layers could be determined in condylar cartilage as five distinctive cellular zones plus the bone area [21,24-26]. Histological observations were categorized in accordance with Kameyama's classification [27] as the mesenchymal cells in the articular fibrous layer and proliferative zone were re-oriented by the physical stretching of posterior fibers of the disc which might trigger the enhanced differentiation and maturation of chondrocytes in the hypertrophic layer, with more chondrogensis; and more endochondral ossification. These changes still reflected the importance and the role of retention time that must be planned through an orthodontic treatment by fixed functional appliances. Proliferative layer activity decreased significantly in the experimental group and these might be due to the increase in mitotic activity of mesenchymal cells of condylar cartilage [1,2]. Furthermore, a very high significant decrease in hypertrophic layer thickness between the experimental sub-groups in the posterior part of the condyle as an adaptive response to the condyle's forward positioning and this is due to cellular morphological changes, not due to an increase in the number of cells [28-30]. Histological observations demonstrated that the subchondral region had more pronounced changes than the central region [23] with adaptive responses to the advancement mandibular displacement. These regional differences could attribute to the impact of growth modification on bone remodeling in the newly formed bone, in contrast to bone remodeling in the pre-existing bone. Thus, the increased mesenchymal cell proliferation triggered a response leading to increase condylar ossification and higher osteoblastic activity at retention period, i.e. progressive decrease in hypertrophic zone will promote process of ossification and ultimately predicting the degree of permanency and stability of the induced modification. Moreover, the regional difference could also be attributed to the change of mechanical environment induced by the advancement

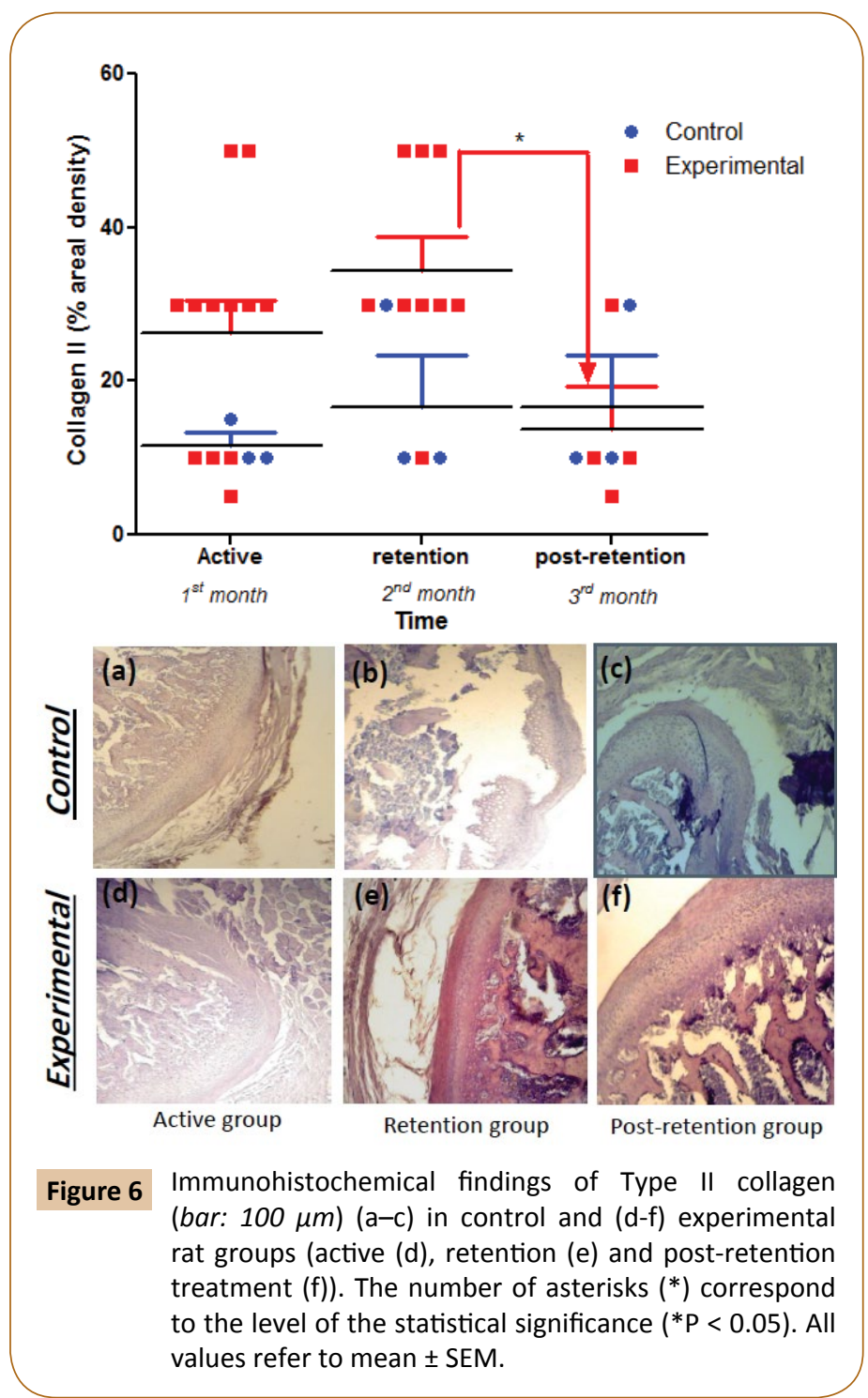



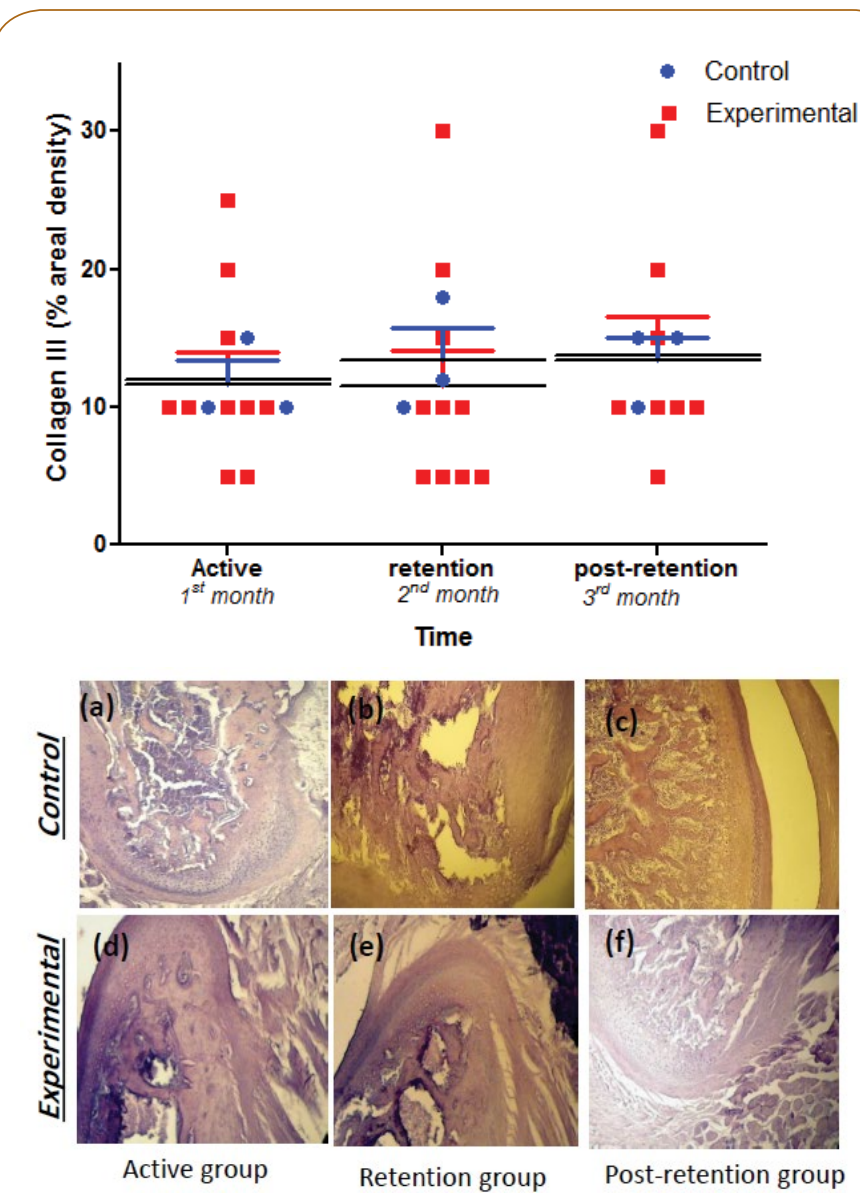

Figure 7 Immunohistochemical findings of Type III collagen (bar: $100 \mu \mathrm{m})(\mathrm{a}-\mathrm{c})$ in control and (d-f) experimental rat groups (active (d), retention (e) and post-retention treatment $(f))$. No statistically significance differences between all groups. All values refer to mean \pm SEM.

of mandibular displacement and it depended on the magnitude and the pattern of the force such as small intermittent, large or continuous compressive force that inhibits condylar growth $[23,30,31]$.

In regard to immunohistochemical findings of collagens, COL-I has non-significantly decreased, and this might support the role of COL-I as a major supporting protein of the TMJ disc that might degrade as osteoarthritis progresses while in COL-II, which is a useful marker for prediction of endochondral ossification, a significant decline in the expression of it in the post-retention period of the experimental group was considered to the intracartilaginous ossification caused by the cellular outgrowth associated with an increase in COL-II expression as a result of release from the inhibition of growth factors. Disturbance in craniofacial growth, including undergrowth of mandible body length, was found in decline of COL-II in mice and this speculated that COL-II is also essential for cartilaginous growth of craniofacial skeleton. Regarding COL-III, there were no great changes in its levels and this was considered to not be involved in cartilage metabolism in TMJ [32-40].

The intracellular expression of MMP-1 was non-significantly increase in the active and the post-retention period reflecting the activity of interstitial collagenase (MMP-1 and MMP-8) due to increasing ages of rats at the end of experiment compared with early stage of experiment and with the control group [41]. Moreover, MMP-8 showed slight and nonsignificant increase in its intracellular expression in both retention and post-retention periods as act with MMP-1 by digesting a number of extracellular matrix and non-extracellular matrix protein [42].

The intracellular expression of MMP-13, which is a key molecule in the regulation of endochondral ossification, hah a significant positive increase in the layer of proliferative, differentiation and hypertrophy in the experimental group in active and retention period $[43,44]$. This revealed the localization of MMP-13 in the layer of condylar cartilage and the specific time of its appearance during the developmental stage which might be essential by chondrocytes enlargement and rapid proliferation and differentiation in condylar cartilage that occurs at a stage before the onset of mineralization $[10,11]$.

The addressing of the main markers that have an important role in the orthodontic remodeling and the stability of the treatment

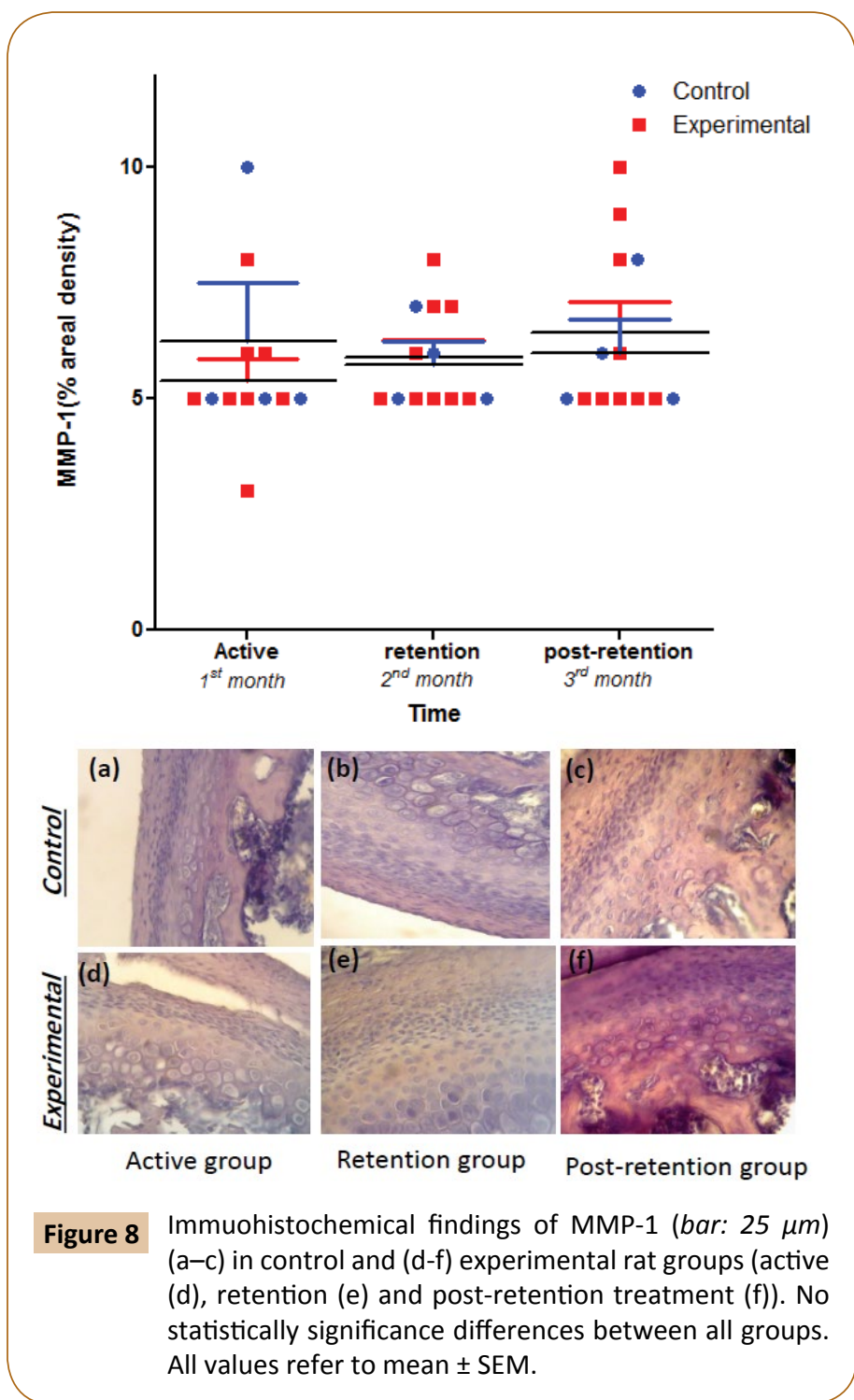




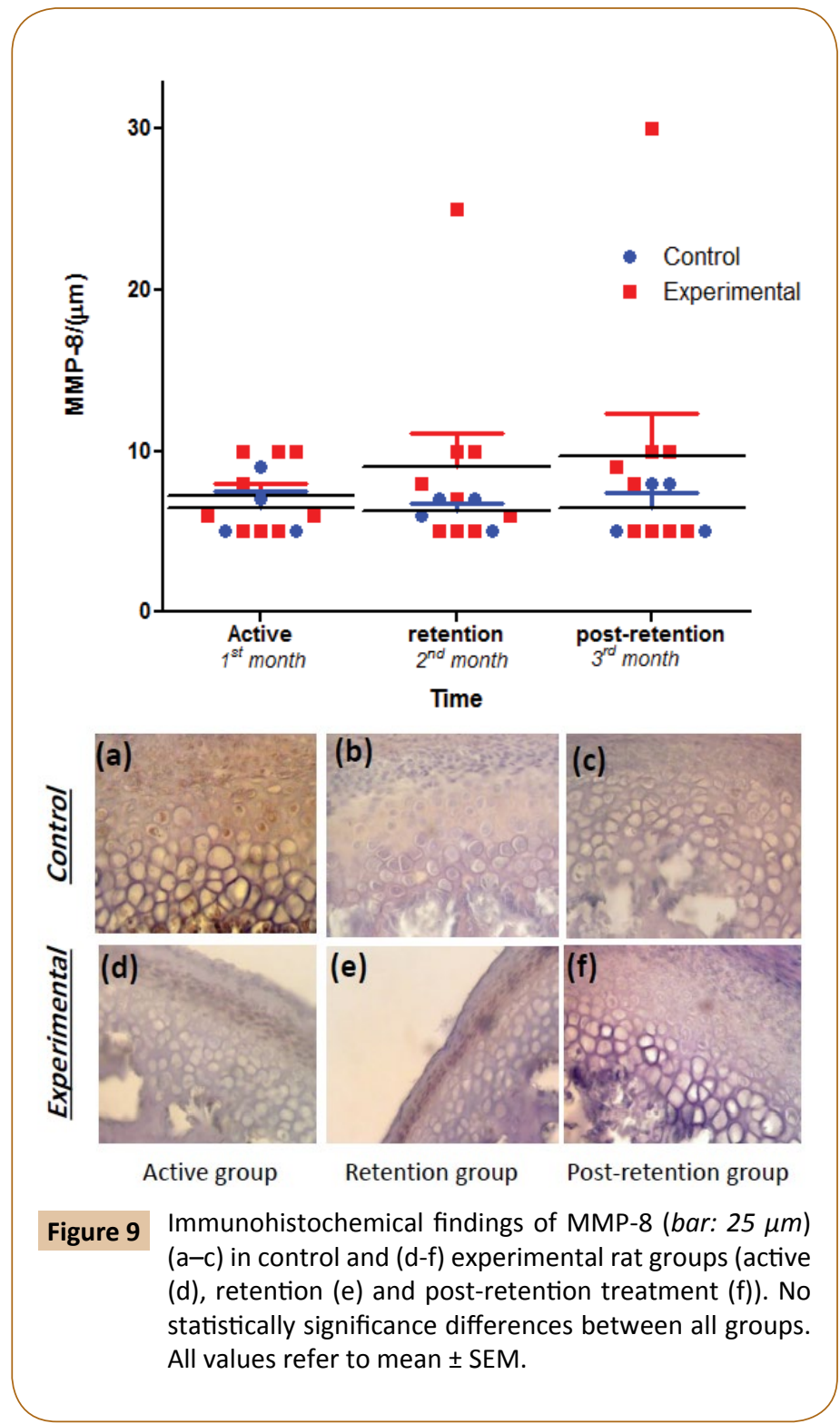

which is confirmed through the post-retention period due to endochondral ossification pattern improvement by shedding more light on the gross and microscopic changes hand by hand with investigating the changes at the molecular level during different and subsequent periods of appliance that ultimately clarifying the role of MMP-13 upregulation with significant reduction in expression of COL-II to control the mandibular condylar cartilage development and remodeling.

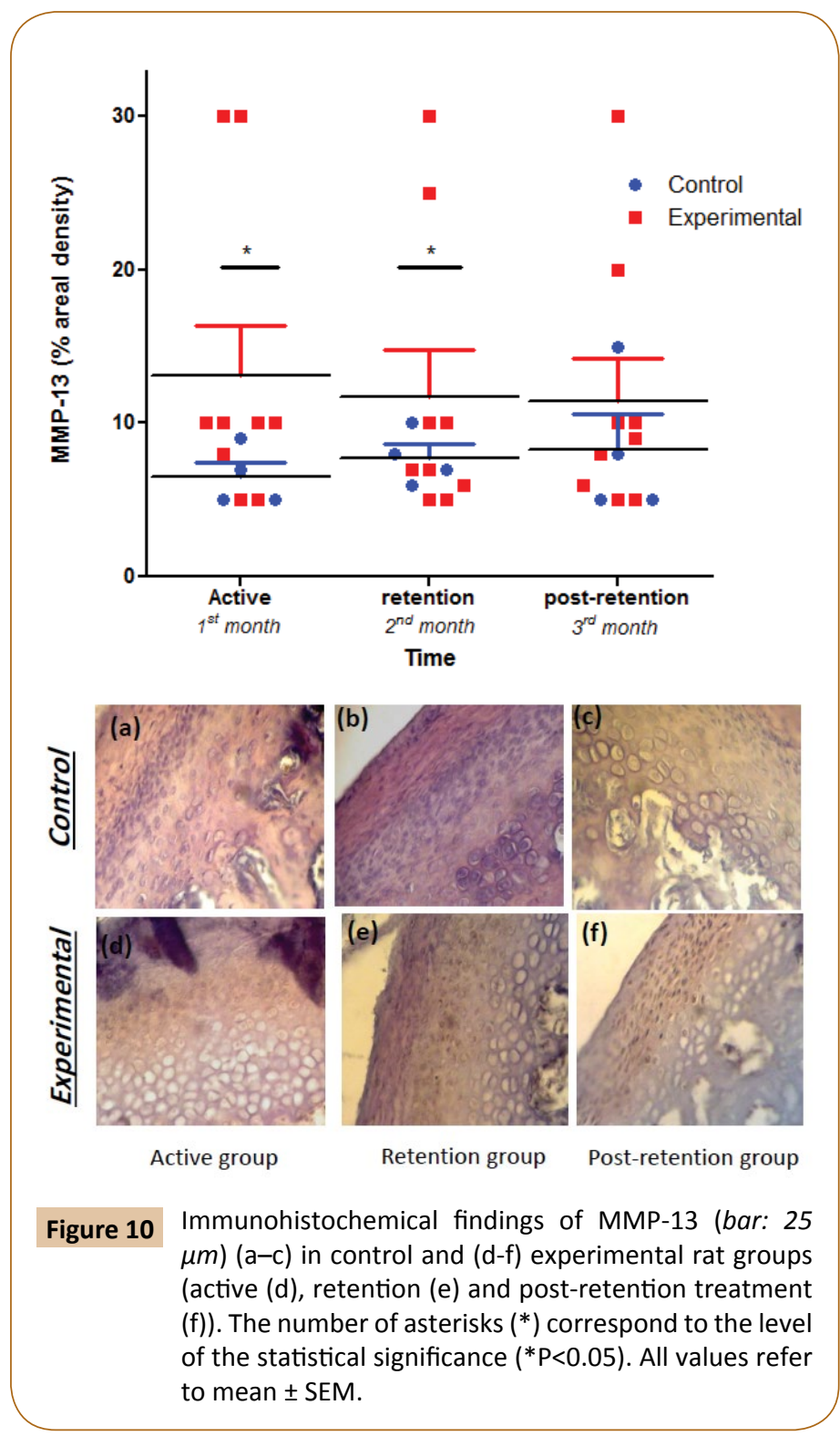

\section{Conflict of Interest}

The authors declare that the article was conducted in the absence of any commercial or financial relationships that could be construed as a potential conflict of interest.

\section{Acknowledgement}

The authors would like to thank Assistant Professor Hssam Alhumadi for his kind help in reading statistical results, and also Professor Marwan Elsaban for his precious important points in the concept of the article. 


\section{References}

1 Grabber TM, Vanarsdall RL, Vig KWL (2005) Orthodontics: Current Principles and Techniques, 4th Edition, St. Louis: Elsevier Mosby Inc., United States.

2 Shum L, Rabie AB, Hagg U (2004) Vascular endothelial growth factor expression and bone formation in posterior glenoid fossa during stepwise mandibular advancement. Am J Orthod Dentofacial Orthop 125: $185-190$.

3 Petrovic AG, Stutzmann JJ, Lavergne JM (1990) Mechanisms of craniofacial growth and modus operandi of functional appliances: a cell-level and cybernetic approach to orthodontic decision making. In: Carlson, D.S. ed. Craniofacial growth theory and orthodontic treatment Monography 23, Craniofacial growth series, Ann Arbor, Michigan, United States.

4 Mayne R, Brewton RG (1993) Extracellular matrix of cartilage: collagen. In: Woessner F, Howell DS, Eds, Joint Cartilage Degradation: Basic and Clinical Aspects: New York, United States.

5 Watanabe A, yamaquchi M, Utsunomya T, Kasaik (2008) Histopathological changes incollage and matrix metalloproteinase levels in articulate condoyle of experimental model rats with Jaw deformity. Orthod Craniofac Res 11: 105-118.

6 Bae JW, Takahashi I, Sasano Y, Onodera K, Mitani H, et al. (2003) Age-related changes in gene expression pattern of matrix metalloprotienases anand their colagenous substrates in mandibular condylar cartilage in rats. J Ant 203: 235-241.

7 Arici S, Akan H, Yakubov K, Arici N (2008) Effects of fixed functional appliance treatment on the tempromandibular joint. Am J Orthod Dentofacial Orthop 133: 809-814.

8 Alexander CM, Howard EW, Bissell MJ, Werb Z (1996) Resuce of mammary epithelial cell apoptosis and entactin degradation by a tissue inhibitor of metalloproteinase 1 transgene. J Cell Boil 135: 1669-1677.

9 Klein T, Bischoff R (2011) Physiology and pathophysiology of matrix metalloproteases. Amino Acids 41: 271-290.

10 Okhubo K, Shimokawa H, Ogawa T, Suzuki S, Fukada K, et al. (2003) Immunohistochemical localization of matrix metalloproteinase 13 (MMP-13) in mouse mandibular condylar cartilage. J Med Dent Sci 50: 203-211.

11 Xu L, Peng H, Wu D, Hu K, Goldring MB, et al. (2005) Activation of the discoidin domain receptor 2 induces expression of matrix metalloproteinase 13 associated with osteoarthritis in mice. J Biol Chem 280: 548-555.

12 Stickens D, Behonick DJ, Ortega N, Heyer B, Hartenstein B, et al. (2004) Altered endochondral bone development in matrix metalloproteinase 13-dificient mice. Development 131: 5883-5895.

13 Rabie AB, Leung FY, Chayanupatkul A, Hagg U, Rabie ABM, et al. (2002) The correlation between neovascularization and bone formation in the condyle during forward mandibular positioning. Angle Orthod 72: 431-438.

14 Rabie AB, She TT, Harley VR, Rabie ABM (2003) Forward mandibular positioning up-regulates SOX9 and type II collagen expression in the glenoid fossa. J Dent Res 82: 725-730.

15 Butterfield RM (1988) New Concepts of sheep growth, University of Sydney, Australia.

16 Xiong H, Hägg U, Tang GH, Rabie AB, Robinson W (2004) The effect of continuous bite-jumping in adult rats: a morphological study. Angle Orthod 74: 86-92.

17 Lawrence A (1960) Manual of histological and special staining technique, Second Edition, McGraw-Hill Book Company, New York, United States.

18 Sato J, Segami N, Yoshitake Y, Kaneyama K, Yoshimura H, et al. (2007) Specific expression of substance $P$ in synovial tissues of patients with symptomatic, non-reducing internal derangement of the temporomandibular joint: comparison with clinical findings. $\mathrm{Br} J$ Oral Maxillofac Surg 45: 372-377.

19 Cozza P, Baccetti T, Franchi L, De Toffol L, McNamara JJA (2006) Mandibular changes produced by functional appliances in Class II malocclusion: A systematic review. Am J Orthod Dentofacial Orthop 129: 599.e1-e12.

20 Shen G, Darendeliler MA (2006) Cephalometric evaluation of condylar and mandibular growth modification: a review. Orthod Craniofac Res 9: 2-9.

21 Chu FT, Tang GH, Hu Z, Qian YF, Shen G (2008) Mandibular functional positioning only in vertical dimension contributed to condylar adaptation evidenced by concomitant expressions of L-Sox5 and type II collagen. Arch Oral Biol 53: 567-574.

22 Arici S, Akan H, Yakubov K, Arici N (2008) Effects of fixed functional appliance treatment on the tempromandibular joint. Am J Orthod Dentofacial Orthop 133: 809-814.

23 Ma B, Sampson W, Wilson D, Wiebkin O, Fazzalari N (2002) A histomorphometric study of adaptive responses of cancellous bone in different regions in the sheep mandibular condyle following experimental forward mandibular displacement. Arch Oral Biol 47: 519-527.

24 Bellus GA, McIntosh I, Smith EA, Aylsworth AS, Kaitila I, et al. (1995) A recurrent mutation in the tyrosine kinase domain of fibroblast growth factor receptor 3 causes hypochondroplasia. Nat Genet 10: 357-359.

25 Hajjar D, Santos MF, Kimura ET (2003) Propulsive appliance stimulates the synthesis of insulin-like groth factors I and II in the mandibular condylar cartilage of young rats. Arch Oral boil 48: 635642.

26 Shen G, Darendeliler MA (2006) Cephalometric evaluation of condylar and mandibular growth modification: a review. Orthod Craniofac Res 9: 2-9.

27 Kameyama Y (1974) Histologic and histometric study of the effect of fluoride on the rat mandibular condyle. J Oral Pathol 3: 205-216.

28 Rabie AB, Leung FY, Chayanupatkul A, Hagg U, Rabie ABM, et al. (2002) The correlation between neovascularization and bone formation in the condyle during forward mandibular positioning. Angle Orthod 72: 431-438.

29 Tang GH, Rabie AB, Hagg U, Rabie ABM (2005) Runx2 regulates endochondral ossification in the condyle during mandibular advancement. J Dent Res 84: 166-171.

30 Tonge EA, Health JK, Meikle MC (1982) Anterior mandibular displacement and condylar growth: An experimental study in the rat. Am J Orthod 82: 277-287.

31 Coprray JCVM, Jansen HWB, Duterloo HS (1985) An in-vitro system for studying the effect of variable compressive forces on the mandibular condylar cartilage of the rat. Arch Oral Biol 30: 305-311.

32 Coprray JCVM, Jansen HWB, Duterloo HS (1985) Effects of 
compressive forces on proliferation and matrix synthesis in mandibular condylar cartilage of the rat in-vitro. Arch Oral Biol 30 299-304.

33 Natiella JR, Burch L, Fries KM, Upton LG, Edsberg LE (2009) Analysis of the collagen I and fibronectin of temporomandibular joint synovial fluid and discs. J Oral Maxillofac Surg 67: 105-113.

34 Grant WT, Wang GJ, Balian G (1978) Type X collagen synthesis during endochondral ossification in the fracture repair. J Biol Chem 262: 9844-9849.

35 Kubokawa T (1994) The mechanism of the articular cartilage degeneration in osteoarthritis. J JPN Orthop Assoc 68: 415-425.

36 Hirota Y, Kawagoe H, Kubota A, Nakagawa M, Itoh T, et al. (1984) Scanning electron microscopic study of changes in the mandibular condyle of growing rats with applied chin cap. J Fukuoka DC 10: 659668.

37 Hollander AP, Heathfield TF, Webber C, Iwata Y, Bourne R, et al. (1994) Increased damage to type II collagen in osteoarthritic articular cartilage detected by a new immunoassay. J Clin Invest 93: 1722-1732.

38 Savontaus $M$, Rintala-Jämsä M, Morko J, Rönning O, Metsäranta $M$, et al. (2004) Abnormal craniofacial development and expression patterns of extracellular matrix components in transgenic Del1 mice harboring a deletion mutation in the type II collagen gene. Orthod Craniofac Res 7: 216-226.

39 Tadashi Fujita, Mao Nakano, Junji Ohtani, Toshitsugu Kawata,
Masato Kaku, et al. (2010) Expression of Sox 9 and typell and X collagens in regenerated condyle. Eur J Orthod 32: 677-680.

40 Dodge GR, Poole AR (1989) Immunohistochemical detection and Immunohistochemical analysis of type II collagene degredation in human normal, rheumatoid and osteoarthritic articular cartilages and in explants of bovine articular cartilages cultured with interlukine-1. J Clin Invest 83: 647-661.

41 Patil A, Sable R, Kothari R (2012) Genetic expression of MMP-Matrixmettalo-proteinases (MMP-1 and MMP-13) as a function of anterior mandibular repositioning appliance on the growth of mandibular condylar cartilage with and without administration of Insulin like growth factor (IGF-1) and Transforming growth factor-B (TGF- $\beta$ ). Angle Orthod 82: 1053-1059.

42 Bae JW, Takahashi I, Sasano Y, Onodera K, Mitani H, et al. (2003) Age-related changes in gene expression pattern of matrix metalloprotienases and their collagenous substrates in mandibular condylar cartilage in rats. J Ant 203: 235-241.

43 Gepstein A, Arbel G, Blumenfeld I, Peled M, Livne E (2003) Association of metalloprotienases tissue inhibitors of matrix metalloprotienases, and proteoglycans with development, aging, and osteoarithritis processes in mouse tempromandibular joints. Histochem Cell Biol 120: 23-32.

44 Okhubo K, Shimokawa H, Ogawa T, Suzuki S, Fukada K, et al. (2003) Immunohistochemical localization of matrix metalloproteinase 13 (MMP-13) in mouse mandibular condylar cartilage. J Med Dent Sci 50: $203-211$. 